\title{
The Development of Thung Fa Bot Weekend Market into Cultural Tourism Attraction in San Pa Tong District, Chiang Mai Province
}

\author{
Thongchai Phuwanatwichit ${ }^{1}$ \\ ${ }^{1}$ Faculty of Humanities, Chiang Mai University, Chiang Mai, Thailand
}

\begin{abstract}
This study aimed to investigate for the socio-cultural and economic context, along with the issues of tourism potentiality of Thung Fa Bot weekend market into the cultural tourism attraction in San Pa Tong District, Chiang Mai Province. A study was created containing Mixed Methodology Research. The data collection was focus group and in-depth interviews from the target population and questionnaires of stakeholders. The study was determined that context of socio-cultural and economic structure, which was relying on farming in the past. The potentiality level to be the cultural tourist attraction in overall was moderate.the aspect of tourist Attraction and Spirit of a community were in high level. On the other hand Accessibility, Activities and Participation civil organizations were in moderate level. There were only the Amenities and Ancillary Services had shown on low level. The results suggested the need to develop its potentiality of cultural tourist attraction in [1] Amenities and Ancillary Services management at the tourist spots and tourism promoting and [2] Linking network with government agencies, private sectors, and communities to join in tourism management in order to enlarge Thung Fha Bod Weekend Market becoming the greater cultural tourism attraction for the tourists.
\end{abstract}

\section{Introduction}

Thung Fa Bot weekend market is the largest cultural weekend market of the North located adjacent to the Highway 108 (Chiang Mai-Hot) on the west side from the kilometer 25-26 near Wat Pa Charoen Tham Temple, Amphur San Pa Tong, Chiang Mai Province. This weekend market is open every Saturday from $1 \mathrm{am}$. until noon. It is called "The Mall" or the shopping mall of the country people. Many people come from everywhere, from different districts and other provinces in the north only to shop at this local market. Thousands of people stroll down to shop at Thung Fa Bot weekend market. It is the place where one can witness so different things that reflect way of living and culture. It is an important cultural tourist destination of Chiang Mai selling various products/goods from pets to consumer commodities such as cattle and buffaloes, native gamecocks, clothing, accessories, handicrafts, food and produce of the forest as well as new and used motorcycles and bicycles.

At present besides being a weekend market, Thung Fa Bot weekend market is like a living community museum, a cultural tourism destination of Amphoe San Pa Tong. Thung Fa Bot weekend market is Lanna cultural weekend market for tourists to explore, shop and admire local dressing. Men wear hats made from fabrics and local materials. People have polite manner and use vernacular 
language. It is cultural heritage that can still be felt. Cultural tourism is crucial to the economic and social development of the country. It is a presentation of activities in combination with tourism, art and culture in both languages, local living pattern through cultural market of the community so that the visitors will share their experiences with the local people and share the consciousness in order to conserve, restore and preserve the cultural heritage of the community. It is a key factor in leading to success in attracting tourists to visit such attractions again and again because of the understanding in the unique value and appreciate the hospitality as well as the culture of the communities in the tourist destinations. Cultural tourism leads to the development of tourist attractions, create jobs and income for local communities and the general public.

Therefore, the development of Thung Fa Bot weekend market to be a major cultural attraction of Amphoe San Pa Tong, Chiang Mai Province as the cultural heritage for the community can attract the public and tourist to shop and enjoy the community. The results of the study will be used to as the guideline for the development of cultural weekend market of Ban Thung Fa Bot in line with community life to prepare for the AEC which is an important factor in determining the direction to sustainable development of local communities as well as maximizing the benefits in terms of economic development, social and cultural of the community to support the expansion of economic, trade, investment, transportation and tourism in the ASEAN region and others regions of the world.

\section{Objectives}

1.To study the contexts of socio-cultural and economic in San Pa Tong District, Chiang Mai Province 2. To study the potentiality of Thung Fa Bot weekend market into the cultural tourism attraction.

\section{Methodology}

This research was conducted using a combination Mixed Methodology Research of qualitative and quantitative methods. The researcher employed the following procedure.

\subsection{Research Scope}

3.1.1 Geographic Scope: The data used in this study were collected in Thung Fa Bot weekend market, San Pa Tong District, Chiang Mai.

\subsubsection{Content Scope:}

1) This study focused on the contexts of socio-cultural and economic in San Pa Tong District, Chiang Mai Province.

2) This study investigated tourism potentiality of Thung Fa Bot weekend market into the cultural tourism attraction.based on the focusing on the aspects of (1) attractions; (2) accessibility; (3) amenities; (4) ancillary services;(5) activities; (6) Spirit of a community and (7) Participation civil organizations.

\subsection{Population and sample groups}

\subsubsection{Population: The researcher designated four groups of stakeholders in Thung Fa Bot weekend} market, San Pa Tong District, Chiang Mai.

1) Public and Private Administrators: A total of 5 administrators in charge of the public mechanisms for tourism development.

2) Market Owner: A total of 2 owner in Thung Fa Bot weekend market. 
3) Merchants: A total of 600 practitioners of merchant and hospitality businesses in Thung Fa Bot weekend market.

4) Foreign and Domestic Tourists: A total of 200 tourists visitor in Thung Fa Bot weekend market.

\subsubsection{Sample Groups: The population was divided into two sample groups.}

1) Merchants: A total of 100 practitioners of merchant and hospitality businesses in Thung Fa Bot weekend market.

2) Foreign and Domestic Tourists: A total of 20 tourists visitor in Thung Fa Bot weekend market.

\subsection{Research and data gathering tools}

3.3.1 Forms for in-depth interviews and focus group were used to elicit data from three target groups, that of public and private administrators, market owner, Merchants and that of foreign and domestic tourists of Thung Fa Bot weekend market.

3.3.2 Potentiality of Cultural Tourist Attraction (Boonlert Chittangwatthana(2005.Page 60-68 ) referred to in Thongchai Phuwanartvichit. 2010) and (Therdchai Chuaybamroong .2009) and Luigi Fusco Girard and Peter Nijkamp. (2009:230) questionnaires based on the (1) attractions; (2) accessibility; (3)amenities; (4)ancillary services;(5)activities; (6)Spirit of a community and(7) Participation civil organizations were distributed to two target groups, that of Merchants, to elicit their opinions. Each question had a rating scale of 1 to 5, with 1 meaning 'least', 2 meaning 'a little', 3 meaning 'fair', 4 meaning 'much' and 5 meaning 'most'. Such a fine scale was intended to elicit as much and as detailed information as possible (Jantanee, 2002:98). As for the criteria used to assess tourism potentiality, the researcher adapted them from the criteria used by the Ministry of Tourism and Sports (Ministry of Tourism and Sports, 2010:62-69) to accommodate tourists. These criteria classified subjects average total scores and levels of Potentiality into three levels, high, medium and low.

\subsection{Data gathering methods}

The researcher collected secondary data from relevant documents, which included academic reports, research, books, articles, journals and on-line databases, using various information sources, such as educational institutions' libraries, research databases, papers, textbooks and other publications.

3.4.1 Field data gathering was conducted using two methods.

1) Observation: Two kinds of observation were practiced: participatory observation, during which the Thung Fa Bot weekend market and non-participatory observation, during which the researcher only observed the environments of the study areas, merchant and tourists' behaviors.

2) Interview: The interviewing method used was of the semi-structured type, with the questions serving as interview guides. In addition, the researcher conducted in-depth interviews in certain situations.

\subsection{Data analysis}

The contexts of socio-cultural and economic were Content Analysis and Potentiality of Cultural Tourist Attraction were used to analyze qualitative data, and descriptive statistics, employing the SPSS programmed, was used to process quantitative data in terms of percentage and means. 


\section{Data analysis and discussion}

\subsection{Social and cultural context}

Thung Fa Bot market was called in Lanna as "Kad Ngua" (Fig. 1 and Fig. 2) It is a place to exchange and trade cows - buffaloes for the use in agriculture. With the context of socio-economic, cultural and agricultural dependent as in the past until the development to be a large weekend market and a major cultural attraction of the north, the cattle-buffaloes market in the north originally established the first time in 1935 at Ban Pa Yang, Amphoe Doi Saket, Chiang Mai. It was open every Tuesday until 1945, the second market at Ban Mae Yoi, Amphoe San Sai, Chiang Mai which was open on Monday and Friday. At a later time, the cattle-buffaloes market was expanded to other provinces in the north including Lampang and Lamphun but in a staggering time. For Thung Fa Bot weekend market, it was founded in 1959, opening regularly on Saturday from morning until afternoon. Many people come from everywhere, from different districts and other provinces in the north only to shop at this local market. It is the place where one can witness so different things that reflect way of living and culture. Especially during major festivals, tourists both Thais and foreigners have come to shop more and more every year because of a its variety.

In the past, there were only a few merchants but nowadays there are over 600 . In each trade around 3,000 locals and tourists enjoy shopping here. During major festivals such as Songkran, Buddhist Lent and Poi Luang the customers can be up to 10,000 with a turnover of 5-10 million Baht. Thung Fa Bot weekend market is located adjacent to the Highway 108 (Chiang Mai-Hot) at Mu 15, Tambon U-wa, Amphoe San Pa Tong, Chiang Mai Province with the market area of 41 rais and is 3 $\mathrm{km}$.From Amphoe San Pa Tong or $22 \mathrm{~km}$. from the city of Chiang Mai.

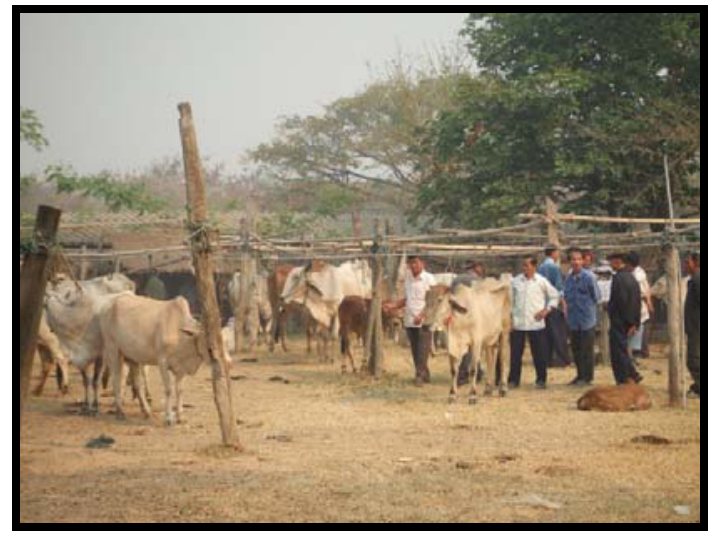

Figure 1. Cattle Market at Thung Fa Bot

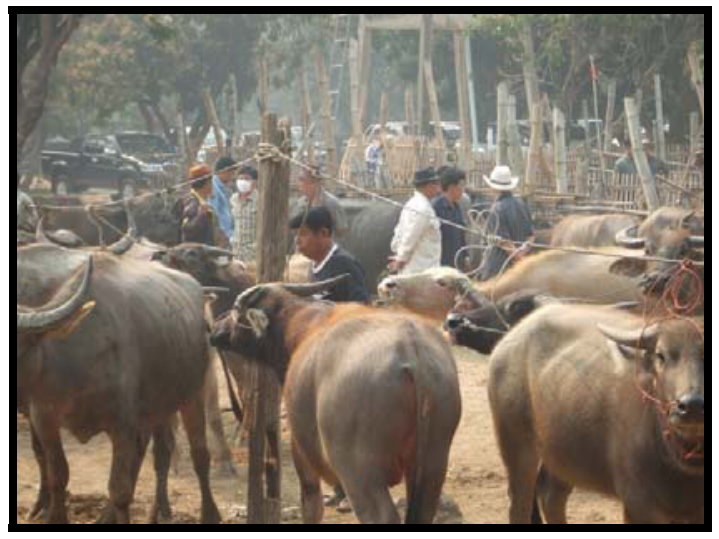

Figure 2. Buffaloes Market at Thung Fa Bot

\subsection{History, background and settlement}

Ban Thung Fa Bot and nearby communities were ancient communities with evidence of settlement and evidence related to the emergence of the San Pa Tong community since 1884 consisting of various ethnic groups, namely, Yonok, Tai Khoen, Yong, Lue, Lua and Chinese from the history of the old story, "Tong Fa Bot" used to be the fertile plains but later turned arid. The rain did not fall to the season. There was just the clouds covering the area but without rainfall. The villages named the area as "Tong Fa Bot" because "Tong" means "Paddy Field and "Fa Bot" means "the dark sky". The whole word thus means the field with the dark sky. Later on, "Tong Fa Bot" was changed to "Thung Fa Bot" as of today. 
The turning point of Thung Fa Bot market starting from the sale of cattle and buffaloes of about 40-60 during the year 1959-1961 and then increased to 80-100 with 10 stores in 1968-1969. It continued to expand with 200-300 cattle and buffaloes at a time with 50 stores during 1970-1972. During 1973-1978, the cattle and buffaloes market of Thung Fa Bot had others goods available. Most of the traders from downtown Chiang Mai and Lamphun brought in consumer products until the market began to change into the its current condition with native gamecocks, fresh food, clothing and vernacular food (Figure 3 and Figure 4 ) as well as bicycles and motorcycles. (Chusit Chuchat, 1995)

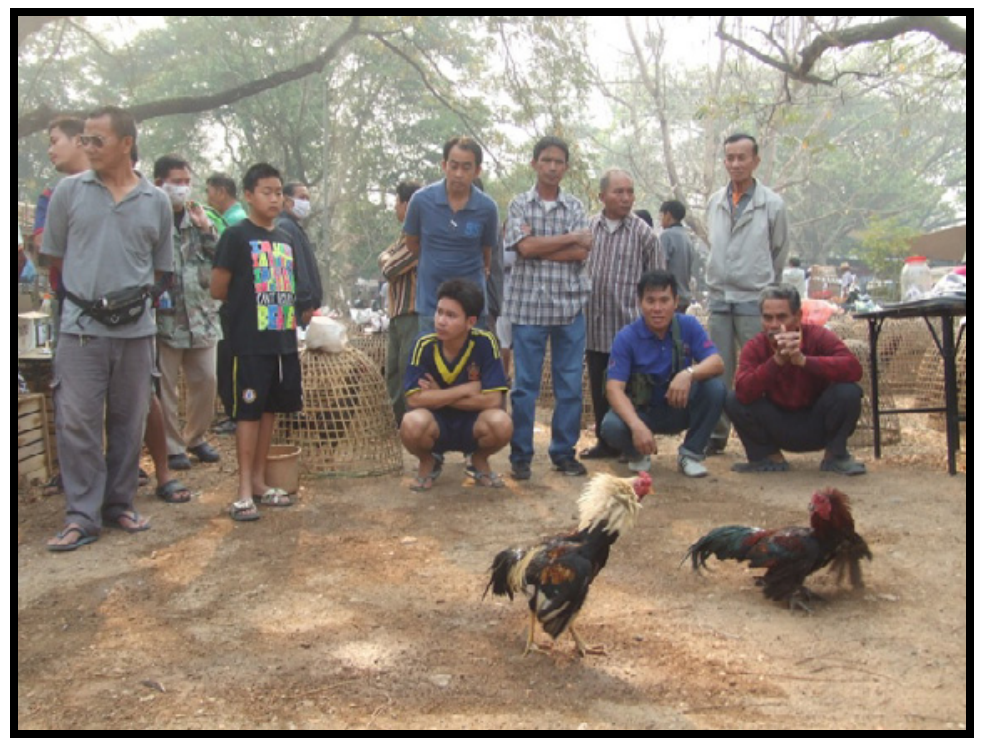

Figure 3. Gamecocks Market

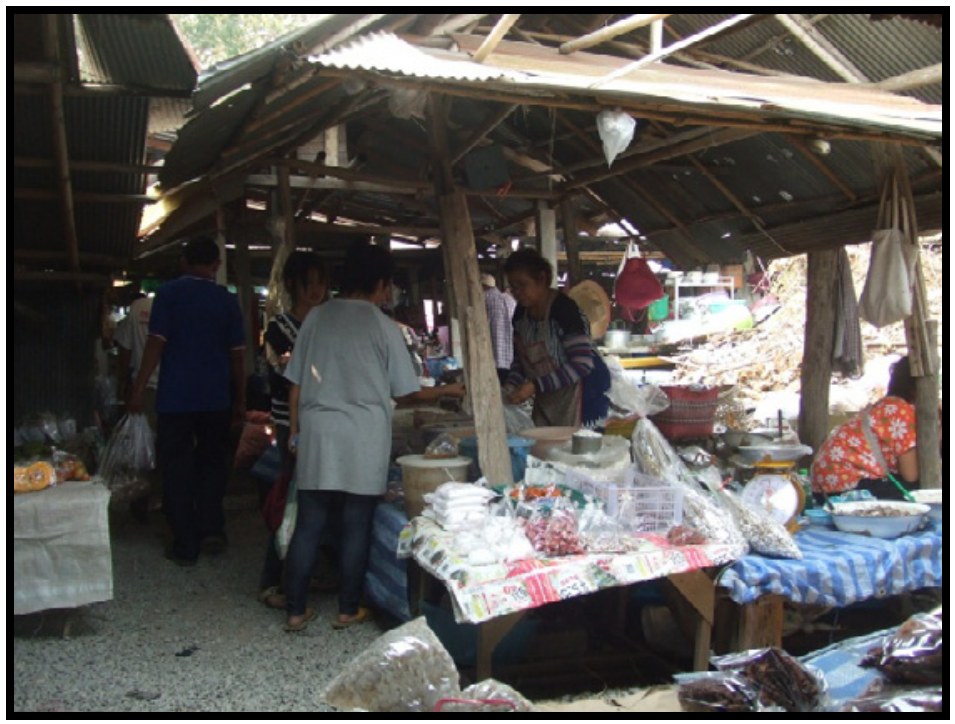

Figure 4. Local Goods Market

Appearance of the buildings and shops at Thung Fa Bot weekend market mostly in the beginning of the market was with wooden pillars and bamboo roof, topped with leave and grass which was the material available locally, cheap and easy to use but the disadvantage was that the lifetime was short and the roof needed to be replaced every 2-3 years. Nowadays, most shops have modified to be 
concrete structure with wooden roof and wrought iron roofed with galvanized sheet or corrugated roofing which has strength and durability. However, some of about 5-6 shops still use leaf or thatch roof depending on the financial condition of each shop. The renters have to bear the expense of building of their own and the owner just acknowledges it. This can be seen by the variety of flexible styles of the structure. The tenants can design to be consistent with the use and durability rather than making the building look beautiful and tidy. Certain merchants also want to conserve the culture and the buildings for their children's education by maintaining tight topped with leaf or thatch roof which has higher prices, and the material is a rarity nowadays.

Trading styles at Thung Fa Bot weekend market are varying. The stall renters in the Thung Fa Bot market has continued to build on the rental space as appropriate and consistent with the trading purpose, Therefore, the social aspect of this market is characterized by local social and economic, ties with kin and trading activity is in mutual dependence which has been inherited from generation to generation. Moreover, very renters would let the stall be rented by the outsiders. There is a dependency between the owner and the stall renters through the payment of yearly or daily rental for each trade helping to create jobs and income for local communities that becomes a local economic interdependence social to this day.

\subsection{Tourism Context}

Since Thung Fa Bot weekend market used to be the important cattle and buffaloes market of San Pa Tong and Chiang Mai, people from places and nearby provinces know this market very well. Therefore, the products sold in the market are well representing the indigenous way of life and dependence on resources within the community.Visitors not only enjoy shopping and observing the lives in particular the commercial culture but the diversity of products as well. Visitors to Thung Fa Bot weekend market are both domestic and foreign tourists, about 200 -300 at a time. Most agree that this market is a reflects the lifestyle and culture of the community especially cattle and buffaloes trade which is the farmers culture that relying on labor from these animals. Therefore, this is truly a living market.Tourists visit this market by getting the information from friends and travel companies that suggested this place as a major cultural attraction of Chiang Mai.

Table 2. Shows the Average Mean on the Potential of Cultural Attraction

\begin{tabular}{|l|c|c|}
\hline \multicolumn{1}{|c|}{$\begin{array}{c}\text { Potentiality of Cultural Tourist } \\
\text { Attraction }\end{array}$} & $\begin{array}{c}\text { Total Average } \\
\text { Potentiality of Cultural } \\
\text { Tourist Attraction }\end{array}$ & $\begin{array}{c}\text { Level of Potentiality of } \\
\text { Cultural Tourist Attraction }\end{array}$ \\
\hline 1. Attractions & 3.65 & High \\
\hline 2. Accessibility & 3.14 & Medium \\
\hline 3. Amenities & 1.89 & Law \\
\hline 4. Ancillary Services & 1.52 & Medium \\
\hline 5. Activities & 3.06 & High \\
\hline 6. Spirit of a community & 3.53 & Medium \\
\hline 7.Participation civil organizations & 3.38 & Medium \\
\hline \multicolumn{1}{|c|}{ Total } & 2.88 & \\
\hline
\end{tabular}

Note: (1) Total Average Scores: The mean total scores of entrepreneurs opinions

(2) Potentiality of Cultural Tourist Attraction Levels: $3.51-5.00=$ high; 2.51-3.50= medium; $1.00-2.50=$ low 


\subsection{The Potential of Thung Fa Bot Weekend Market as the Cultural Attraction}

(Table 2.) The potential of cultural tourist attraction of Thung Fa Bot weekend market in San Pa Tong District, Chiang Mai Province are based on the Attractions, Accessibility, Amenities, Ancillary Services, cooperation of the community and participation of local administrations. Overall potential is moderate. The attractions and cooperation of the community were in high level. The Accessibility, Activities and community participation were in moderate level. Only the Amenities and Ancillary Services are in low level.

When considering in detail, Attractions has high potential since there are a number of traditional trades such as cattle/buffaloes market, native gamecocks selling as well as the selling of agricultural tools such as spades, knives (machetes), axes, hammers, and so on.

Accessibility, Activities and Community Participation are in moderate level since the quality of routes accessible to the attractions and walkways are narrow. Promotional activity for tourism is very limited only the folk music. The participation of communities in conservation of the remaining architecture in the community is rather low.

Amenities and Ancillary Services had shown on low level since the parking space is cramped, toilets are not clean enough and the accommodation for tourist is not adequate. ATM service is not enough to accommodate the tourists. The advertising through various media both inside and outside the country is not consistent.

However,the application of Potentiality of Cultural Tourist Attraction of Thung Fa Bot weekend market in San Pa Tong District, Chiang Mai Province, showed that the development of tourism amenities and ancillary Services was most necessary; second to these were development of tourism accessibility, activities and Participation civil organizations.

\section{Recommendations}

According to this study, some suggestions can be made. In the near future, the opening of ASEAN. in 2016 will result in an increased number of tourists to Chiang Mai, especially Chinese tourists, which will have both positive and negative impact on tourism development. Therefore, the government should develop tourism infrastructure, improve its potentiality of cultural tourist attraction in (1) Amenities and Ancillary Services management at the tourist spots and tourism promoting and (2)Linking network with government agencies, private sectors, and communities to join in tourism management in order to enlarge Thung Fha Bod Weekend Market becoming the greater cultural tourism attraction for the tourists.

\section{Conclusion}

The study was determined that Thung Fa Bot weekend market was originally called 'Kad Nguao' (cow market) and born in 2502 B.E. It was a place to trade cows as a labor for agricultural sector. With the context of social, cultural, and economic structure, which relied on farming in the past, making this place to become the huge weekend market which is an important cultural tourist attraction for the community nowadays. This market opens on Saturdays from morning to afternoon. They sale different kinds of goods such as cows, buffaloes, pets, local gamecocks, clothes, accessories, handicrafts and food it is also the biggest new and used car, bicycle, and motorcycle market in the north of Thailand. The weekend market's potentiality level to be the cultural tourist attraction in overall was moderate. The attraction and Spirit of a community were in high level.The Accessibility, Activities and community participation were in moderate level. There were only the Amenities and Ancillary Services had shown on low level. However, the application of Potentiality of Cultural Tourist Attraction of Thung Fa Bot weekend market in San Pa Tong District, Chiang Mai Province, 
showed that the development of tourism amenities and Ancillary Services was most necessary; second to these were development of tourism accessibility, activities and Participation civil organizations.

\section{References}

1. Boonlert Chittangwatthana,. Sustainable Tourism Development. (First edition). Bangkok: Tourism Academic Center (2005). [Thai]

2. Jantanee, Aphinan. 2002. Business Research. Faculty of Management, Raja baht Institute. Bangkok: Phithak Aksorn, p 98.

3. Luigi Fusco Girard and Peter Nijkamp,. Cultural Tourism and Sustainable Local Development. Ashgate PublishingCompany Suite 420. (2009).

4. Prasithrathasinth, Suchart. 2001. Social Sciences Research Methodology. Bangkok: Chulalongkorn University Press, p 134.

5. Therdchai Chuaybamroong,. The Role of Local Government in Sustainable Tourism Development on the Concept of Sufficiency Economy. Cabinet and Royal Gazette Publishing, Bangkok.( 2009)

6. Thongchai Phuwanatwichit,. Integrated Strategic Tourism Development Strategy on R3A (Chiang Rai- Kunming). Doctoral dissertation, Doctor of Philosophy, Social Science, Mae Fah LuangUniversity.( 2010)

7. Tourism Authority of Chiang Rai, Luang Nam Tha Tourism Room, Tourism Authority of Yunnan, 2008 